\title{
Minocycline trial in japanese encephalitis: a double blind, randomized placebo study
}

\author{
Singh $\mathrm{A}^{1}$, Mehta $\mathrm{A}^{2}$, Kushwaha $\mathrm{KP}^{3}$, Pandey $\mathrm{AK}^{4}$, Mittal $\mathrm{M}^{5}$, Sharma $\mathrm{B}^{6}$, Pandey $\mathrm{J}^{7}$ \\ ${ }^{1}$ Dr Abhishek Kumar Singh, Lecturer, B. R. D Medical College, Gorakhpur, UP, India, ${ }^{2}$ Dr Anita Mehta, Associate \\ Professor, B. R. D Medical College, Gorakhpur, UP, India, ${ }^{3}$ Dr K P Kushwaha, Ex Prof \& Head, B. R. D Medical \\ College, Gorakhpur, UP, India, ${ }^{4}$ Ashok Kumar Pandey, Scientist C, National Institute of Virology, Gorakhpur Unit, \\ Gorakhpur, UP, India, ${ }^{5}$ Dr Mahima Mittal, Associate Prof \& Head, ${ }^{6}$ Dr Bhoopendra Sharma, Associate Professor, \\ Department of Pediatrics, B. R. D Medical College, Gorakhpur, UP, India, ${ }^{7}$ Dr Jayesh Pandey, Lecturer, Department of \\ Microbiology, B. R. D. Medical College, Gorakhpur, UP, India.
}

Address for Correspondence: Dr. Anita Mehta, Associate Professor, Dept of Pediatrics, BRD Medical College, Gorakhpur, UP, India. Email: 25anitamehta@gmail.com

\begin{abstract}
Objective: To evaluate the effect of minocycline in Japanese Encephalitis (JE) patient on reduction in mortality, neurological deficit and behavioral outcome. Design: Double blind randomized placebo control trial. Setting: Tertiary level hospital. Inclusion criteria: Only JE patients who were IgM positive for JE Virus (JEV) in cerebrospinal fluid and/or serum were included. Exclusion criteria: Those clinically suspected JE patients who were IgM negative for JE Virus (JEV) in cerebrospinal fluid and serum were excluded. Patients were selected randomly. Intervention: A total of 44 patients of JE of the age range between 1-13yr were divided equally in two groups A and B. Group A received drug under study, that is minocycline, and Group B received placebo. Outcome measures: The present study was designed to: compare the clinical course during hospitalization and after discharge in terms of duration of symptoms, death and disability at the time of discharge, outcome of the intervention on clinical recovery, behavioral problems and neurological deficit after 12 month of follow up. Results: Duration of fever, unconsciousness and total duration of hospital stay were significantly reduced in Group A (minocycline) patients. Conclusion: Minocycline has significant beneficial effect in JE patients in duration of major symptoms and duration of hospital stay. However, the mortality rate and prevalence of neurological deficits and behavioral problems on a 12 months follow up remain unchanged.
\end{abstract}

Key words: Japanese Encephalitis Virus, Minocycline, Viral etiologies.

\section{Introduction}

Japanese encephalitis virus (JEV) is a leading cause of viral encephalitis in Asia, with around 50,000 cases and 15,000 deaths per year in children below 15 years of age. Case fatality averages $30 \%$ and a high percentage of the survivors are left with permanent neuropsychiatric sequelae [1]. JE epidemics has been occurring almost every year in Gorakhpur and adjoining districts of Uttar Pradesh [2]. No specific antiviral drug is available till today; the prophylactic strategies remain the only option to prevent the JE, of which human vaccination is one. The vaccination has its own limitation of improper handling, coverage, non-

Manuscript received: $14^{\text {th }}$ April 2016

Reviewed: $27^{\text {th }}$ April 2016

Author Corrected; $10^{\text {th }}$ May 2016

Accepted for Publication: $24^{\text {th }}$ May 2016 responders and the availability. In order to develop the drug for treatment of JE patients, different therapeutic measures like, Rosmarinic acid, Interferon, Curcumin Glycosidase inhibitors, Minocycline and siRNA have been tried in JE animal models [3-7]. Oral ribavarin has also been tried on JE patients [8].

Minocycline is a semi-synthetic second generation tetracycline that has proven effective not only for the conventional treatment of bacterial infections, but also for treatment of inflammatory conditions [9]. Because of its relatively small size (495Da) and highly lipophilic nature, minocycline crosses the blood-brain barrier (BBB) with ease and penetrate the cerebrospinal fluid (CSF) of human beings. Their neuroprotective and anti- 
inflammatory effects have generated considerable interest to study its effect on neurodegenerative disorders as well as viral induced CNS infection [1014]. It was first shown to be protective in human immunodeficiency virus (HIV) infections [15]. In animal models or in vitro systems of flaviviral infections (especially Japanese encephalitis virus and West Nile virus), minocycline has been shown to be highly effective [16,17]. Owing to the fact that minocycline is well tolerated by most people and that the drug has nearly 40 year's history of usage, it is an exciting task to perform the clinical trial in JE patients. Therefore, in the present double-blind, placebocontrolled study, we sought to evaluate the efficacy of minocycline in JE patients.

\section{Materials and Methods}

This trial was performed at Nehru Hospital of BRD Medical College, Gorakhpur, Uttar Pradesh India, from July 2008 to August 2009. The study protocol was evaluated and approved by the institutional ethics committee and well informed written consent was taken from attendants/ guardians of each patient, ensuring their full confidentiality. A sample size of 44 patients was obtained using Gehan chart at $\alpha=0.05$ and power of test $=0.80$. The response rates assumed were 0.05 and 0.25 for the placebo and minocycline respectively. Briefly, 280 patients admitted to the hospital with clinically suspected JE were selected, based on the signs and symptoms in the first phase of the screening procedure. Out of 280, a total of 50 patients who were $\mathrm{IgM}$ positive for $\mathrm{JE}$ in cerebrospinal fluid and/or serum were included in the study. IgM antibodies against JE viruses were detected by standard ELISA [18]. Briefly, IgM from patient CSF and sera were captured on antihuman IgM-coated wells, and JE virus antigen was added overnight at $4^{\circ} \mathrm{C}$. The captured antigens were probed with biotin-labeled flaviviruses cross-reactive monoclonal antibody (MAb) HX-2 and avidin horseradish peroxidase.

Hydrogen peroxide and $O$-phenylene diamine (OPD) were used as substrate and chromogen, respectively. Reaction was terminated using $4 \mathrm{~N} \mathrm{H}_{2} \mathrm{SO}_{4}$ and read at $492 \mathrm{~nm}$. The test included known strong- and weakpositive samples as positive controls, and JEV IgMnegative samples were used as negative controls. Specimens giving a signal to noise $(\mathrm{S} / \mathrm{N})$ ratio of $>2$ were treated as positives. Out of $50 \mathrm{JE}$ IgM positive patients, six refused to participate in the study. Finally 44 patients were recruited for the trial study.
After recruitment, the patients were randomly distributed into two equal groups, A (minocycline trial) and B (placebo) using a random number table. Slips bearing the random allocation were placed in opaque envelopes, sealed and numbered serially outside. Drug under study and placebo were given in a packed name ' $A$ ' and ' $B$ ' respectively. Observer and the patient did not know about the drug.

All the patients were admitted and managed according to Institutional management protocol of AES. Group A patients also received minocycline in the dose of 5-6 $\mathrm{mg} / \mathrm{kg}$ in two divided doses for 10 days through feeding tube, which was started from the day of admission. Patients in the placebo group received the capsules of similar color and appearance but filled with grinded sugar. Placebo was also started from the day of admission.

A detailed clinical profile of the patients in both the groups was made that included clinical presentation, detailed neurological examination, management and outcome of the patients. Data regarding mortality, total duration of hospital stay, neurological deficit and behavioral outcome were collected by another investigator. Patients were assessed at the time of discharge by "Liverpool outcome score" [19].

They were followed up for a period of one year 12 months during which neurological deficits and behavior problems were assessed. Neurological deficits were assessed by clinical neurological examinations, and these were divided in five groups including higher cerebral functions including mental retardation and impairment of memory, speech disturbances, extra pyramidal features including abnormal posture and hyperkinetic movements, pyramidal tract feature including paralysis and cranial nerve palsies. Seizure was not assessed because patients were under the control of antiepileptic drug (sometimes > one drug) during entire period of intervention and follow up. Behavior was assessed by "Child Behavior Checklist" [20] for age groups 2 to $3 y r$ and 4 to $18 \mathrm{yr}$. Scores were considered as normal below 95 percentile, clinically significant above 98 percentile and borderline between 95 to 98 percentile.

Statistical method: Proportion Z-test, Student's t-test, Chi-square test, Kaplan Meier analysis and Log rank test were used. $p$ value of less than 0.05 was considered significant. 


\section{Results}

A total of 44 patients, positive for anti JE IgM in CSF and/ or serum were selected from 280 clinical suspects of Japanese encephalitis. The mean ages of patients in Group A and B were 7.65 \pm 2.40 and $6.31 \pm 3.42$ years respectively. Similarly, the sex distribution (M: F) in Group A was 13: 9 and in Group B was 15: 7.

Except for exaggerated muscle tone $(\mathrm{p}<0.05)$, other neurological characteristics like level of consciousness, presence and absence of meningeal irritation signs, abnormal limb movements, deep tendon reflexes and plantar response of the two groups were unassociated $(\mathrm{p}>0.05)$ as calculated by chi-square test.

No statistical association was found between two groups regarding routine laboratory findings such as haemoglobin (gm\%), total leukocyte count (per cu/mm), differential neutrophil count (\%), differential lymphocyte count (\%), SGOT (IU/dl) and serum creatinine (mg/dl) except SGPT (IU/dl ), where Chi-Square test is significant $(\mathrm{P}<0.05)$.

There was no statistical association $(\mathrm{p}>0.05)$ between two groups regarding cerebro-spinal fluid findings of total and differential leucocyte counts, protein and sugar level.

Table 1 shows the mean duration and standard deviation of symptoms in Group A (minocycline) and Group B (placebo) patients. The mean duration of all symptoms was less in Group A in comparison to Group B. However, only the difference in mean duration of fever and mean duration of unconsciousness were found to be statistically significant ( $p<0.05$ and $p<0.01$ respectively). Although the duration of vomiting and convulsions were less in Group A, the difference were not statistically significant $(\mathrm{p}>0.05)$.

Table 1: Group-wise distribution of patients according to duration of symptoms.

\begin{tabular}{|c|c|c|c|c|c|c|c|c|}
\hline \multirow[t]{2}{*}{ Symptoms } & \multirow[t]{2}{*}{ Group } & \multicolumn{5}{|c|}{ Duration ( Days ) } & \multicolumn{2}{|c|}{$\begin{array}{c}\text { t-Test } \\
(\text { d.f. }=42)\end{array}$} \\
\hline & & $\mathbf{0}$ & 1- 8 & $8-22$ & Mean & Sd & $\mathbf{t}$ & $\mathbf{p}$ \\
\hline \multirow[t]{2}{*}{ Fever } & A & 1 & 18 & 3 & 5.72 & 3.80 & \multirow[b]{2}{*}{2.19} & \multirow[b]{2}{*}{$<.05$} \\
\hline & $\mathrm{B}$ & 0 & 13 & 9 & 8.79 & 5.16 & & \\
\hline \multirow[t]{2}{*}{ Convulsion } & $\mathrm{A}$ & 0 & 20 & 2 & 5.45 & 3.01 & \multirow[b]{2}{*}{1.48} & \multirow[b]{2}{*}{$>.05$} \\
\hline & $\mathrm{B}$ & 2 & 13 & 7 & 7.43 & 5.32 & & \\
\hline \multirow[t]{2}{*}{ Unconscious } & $\mathrm{A}$ & 8 & 13 & 1 & 3.34 & 3.32 & \multirow[b]{2}{*}{2.37} & \multirow[b]{2}{*}{$<.01$} \\
\hline & B & 5 & 10 & 7 & 6.81 & 5.85 & & \\
\hline \multirow[t]{2}{*}{ Vomiting } & $\mathrm{A}$ & 16 & 5 & 1 & 1.70 & 3.45 & \multirow[b]{2}{*}{0.84} & \multirow[b]{2}{*}{$>.05$} \\
\hline & B & 17 & 1 & 4 & 2.93 & 5.76 & & \\
\hline
\end{tabular}

Table 2 shows Group-wise distribution of patients according to GCS scores at time of admission. It is observed that patients in each GCS score group were evenly distributed in both Groups at the time of admission. The mean \pm s.d of GCS score of group A was $6.32 \pm 4.05$ and group B was $4.86 \pm 2.19$. The p value obtained by unpaired student t-test was 0.15 (non significant).

Table 2: Group-wise distribution of patients according to GCS scores at time of admission.

\begin{tabular}{|c|c|c|c|c|c|}
\hline & & & At a & sion & \\
\hline GCS Score & Group A & $($ Mean \pm S.D $)$ & Group B & (Mean \pm S.D & $\begin{array}{c}\text { p-value } \\
\text { (Unpaired Student t-test) }\end{array}$ \\
\hline 3 & 15 & \multirow{4}{*}{$6.32 \pm 4.05$} & 16 & \multirow{4}{*}{$4.86 \pm 2.19$} & \multirow{4}{*}{$\begin{array}{c}\mathrm{T}=1.48 \\
\mathrm{df}=42 \\
\mathrm{p}=0.15(\mathrm{NS})\end{array}$} \\
\hline $4-8$ & 5 & & 4 & & \\
\hline $9-15$ & 2 & & 2 & & \\
\hline Total & 22 & & 22 & & \\
\hline
\end{tabular}


Table 3 shows mean duration and standard deviation of hospital stay in patients from both Groups. The mean duration of stay in hospital for patients from Group A (13.84 day \pm 5.68$)$ was significantly lower $(\mathrm{p}<0.05$.) than patients from Group B (21.59 day \pm 14.87$)$.

Table 3: Group-wise mean distribution of stay in hospital before discharge.

\begin{tabular}{|c|c|c|c|}
\hline & $\begin{array}{c}\text { Mean duration of stay in } \\
\text { hospital (days) }\end{array}$ & SD & t; df; p \\
\hline Group A (n=20) & 13.84 & 5.68 & $\begin{array}{c}\mathrm{t}=2.11 ; \\
\mathrm{df}=34 ; \\
\mathrm{p}=0.04(\mathrm{~S})\end{array}$ \\
\hline Group B (n=17) & 21.59 & 14.87 & \multirow{2}{*}{. } \\
\hline
\end{tabular}

Table 4 shows Group-wise evaluation of patients at discharge from hospital. Although mortality rate was less and rate of full clinical recovery was higher in patients from Group A in comparison to Group B, but these differences were not statistically significant ( $p>0.05$ ). Two patients in group A and 3 patients in Group B were lost during follow up. Remaining patients (group A-20, group B-17) were followed up for a period of 12 months.

Table 4: Group-wise evaluation of patients at discharge from hospital.

\begin{tabular}{|c|c|c|c|}
\hline Evaluation of patients at discharge & Group A, $(n=22)$ & Group B, $(n=22)$ & $\chi^{2} ; \mathbf{d f} ; \mathbf{p}$ \\
\hline Death & 2 & 5 & \multirow{3}{*}{$\begin{array}{l}\chi^{2}=1.65 \\
\mathrm{df}=2 \\
\mathrm{p}=0.44(\mathrm{NS})\end{array}$} \\
\hline Complete clinical recovery & 14 & 11 & \\
\hline Partial clinical recovery & 6 & 6 & \\
\hline
\end{tabular}

Two patients in group A and 3 patients in Group B were lost during follow up. Remaining patients (group A-20, group B-17) were followed up for a period of 12 months.

Table 5: Group-wise persistence of Behavioral Problems and Neurological Deficit during follow up.

\begin{tabular}{|c|c|c|c|c|}
\hline \multicolumn{5}{|c|}{ Residual Behavioral problems during period of follow-up } \\
\hline & 1-2 weeks & 4-6 weeks & 6-26 weeks & 26-52 weeks \\
\hline Group A $(n=19)$ & $5(26.3 \%)$ & $3(15.8 \%)$ & $1(5.3 \%)$ & $0(0)$ \\
\hline Group B $(n=17)$ & $6(35.3 \%)$ & $5(29.4 \%)$ & $3(17.6 \%)$ & $2(11.8 \%)$ \\
\hline $\begin{array}{l}\text { Odds Ratio } \\
(95 \% \mathrm{CI})\end{array}$ & $\begin{array}{c}1.53 \\
(0.37-6.35)\end{array}$ & $\begin{array}{c}2.22 \\
(0.42-13.00)\end{array}$ & $\begin{array}{c}3.86 \\
(0.36-41.20)\end{array}$ & (undefined) \\
\hline \multicolumn{5}{|c|}{$\begin{array}{l}\text { Log-rank (Mantel-Cox) test for equality of residual behavioral problems in the two groups } \chi^{2}=1.786 ; \mathrm{df}=1 \text {; } \\
\qquad \mathrm{p}=0.1814 \text { (NS) }\end{array}$} \\
\hline \multicolumn{5}{|c|}{ Persistent Neurological deficit during period of follow-up } \\
\hline & 1-2 weeks & 4-6 weeks & 6-26 weeks & 26-52 weeks \\
\hline Group A $(n=19)$ & $8(42.1 \%)$ & $4(21.1 \%)$ & $4(21.1 \%)$ & $2(10.5 \%)$ \\
\hline Group B $(n=17)$ & $7(41.2 \%)$ & $6(35.3 \%)$ & $5(29.4 \%)$ & $4(23.5 \%)$ \\
\hline $\begin{array}{l}\text { Odds Ratio } \\
(95 \% \mathrm{CI})\end{array}$ & $\begin{array}{c}0.96 \\
(0.26-3.63)\end{array}$ & $\begin{array}{c}2.05 \\
(0.46-9.03)\end{array}$ & $\begin{array}{c}1.56 \\
(0.34-7.13)\end{array}$ & $\begin{array}{c}2.62 \\
(0.41-16.54)\end{array}$ \\
\hline \multicolumn{5}{|c|}{ Log-rank (Mantel-Cox) test for equality of persistent neurological deficit in the two groups } \\
\hline
\end{tabular}




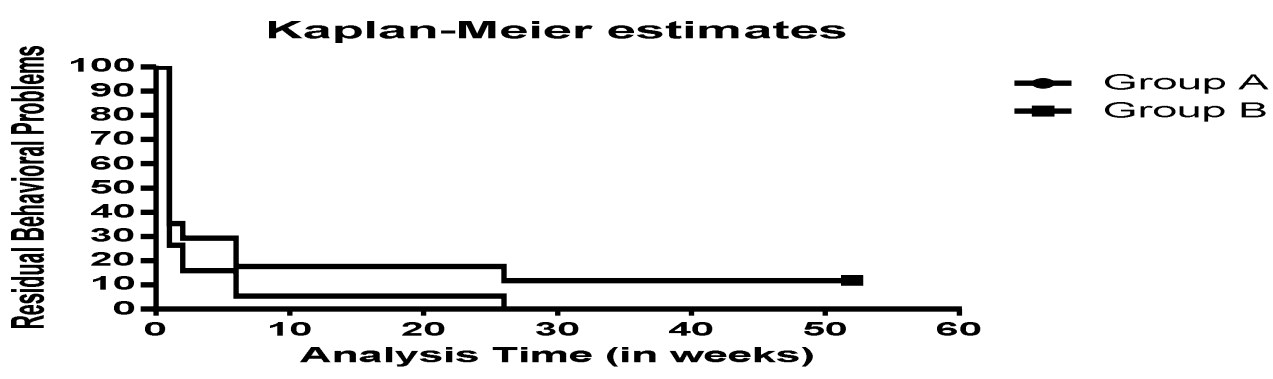

Figure-1: Kaplan Meier estimates for residual behavioral problems during 12 month follow up

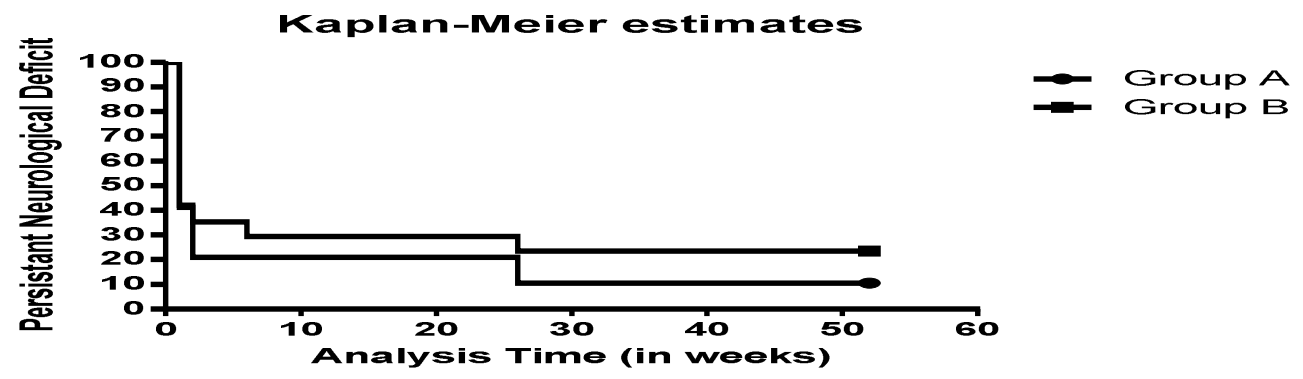

Figure-2: Kaplan Meier estimates for persistent neurological deficit during 12 month follow up

Table 5 shows the Group-wise persistence of behavioral problems and neurological deficits in patients discharged from hospital during twelve months (52 week) of follow-up. The prevalence of behavioral problems was less in patients from Group A at every point of observation during the 12 month follow-up in comparison to patients from Group B (OR of 1.53, 2.22 and 3.86 at 2 weeks, 6 weeks and 26 weeks respectively). However, analyzing the Kaplan Meier estimates of the above data using a log-rank test for equality of residual behavioral problems in the two groups, this difference was found to be insignificant ( $\mathrm{p}>0.05)$. Similarly, the persistence of neurological deficit was less in patients from Group A at every point of observation during the 12 month follow-up in comparison to patients from Group B (OR of 0.96, 2.05, 1.56 and 2.62 at 2 weeks, 6 weeks, 26 weeks and 52 weeks respectively).

However, this difference in Kaplan Meier estimates was found to be insignificant ( $\mathrm{p}>0.05$ ) on performing a log-rank test for equality of persistent neurological deficit in both groups. In our patients behavior problems included abusive language, aggressive behavior, irrelevant talk, biting, laughing without reason and excessive cry. Neurological deficit were in the form of impairment of memory, mental retardation, speech defects, extra pyramidal sign, involuntary movement, hemiparesis and cranial nerve palsies.

\section{Discussion}

The simple way to find a new drug is to start with an old one. Minocycline is a semi-synthetic tetracycline derivative which has proven history of use as an antibacterial and also as a neuroprotective agent [21]. The antiviral role of minocycline has generated considerable interest from the last decade [22]. Despite of many studies of minocycline as an antiviral drug, probably no study till date is available on direct effect of minocycline in humans suffering with JE infection [23]. In the present study, we showed that minocycline has beneficial effects in JE patients by reducing duration of symptoms like fever and unconsciousness and mean duration of hospital stay. The neurological features of patients of both groups were statistically not associated except the muscle tone. Also, there was no statistical correlation between the groups in the routine laboratory investigations of serum \& CSF. Even distributions of GCS score in two groups at time of admission support the unbiased outcome in both groups. It was observed that the duration of fever and hospital stay were significantly less in the minocycline treatment group as compared to the placebo group. This may be attributed to the anti-inflammatory \& neuroprotective property of the minocycline. Studies by various 
researchers in different model systems have reported the different mechanism of action of minocycline like inhibition of microglial activation, diminishing the production of proinflammatory interleukins in the brain, preventing the damage of blood brain barrier and inhibition of neuronal apoptosis [24-27]. At the time of discharge full clinical recovery was found in $63.65 \%$ and $50 \%$ of patients in group A and B respectively, and mortality was found in $9.0 \%$ and $22.7 \%$ patients in group A and B respectively. Decreased mortality and increased full clinical recovery in our study may be because of availability of advanced life support and early referral facility of patients from remote areas.

There was no significant difference of neurological deficits and behavior problems in two groups after ene year 12 months of follow up. At the time of discharge 5 (25.0\%) patients in Group A and 6 (35.3\%) in Group B having behavior problems which were gradually improved during ene year 12 months of follow up and only $2(11.8 \%)$ patients in group B were remained with behavior problems in the form of aggressive behavior. In a study done by Sarkari et al. in adult JE patients, $78.0 \%$ patients remained with psychological problems after one year of follow up [28]. Eight (40.0\%) patients in group A and $7(41.2 \%)$ patients in group B were having some form of neurological deficits at the time of discharge, these were also gradually improved during the period of ene year 12 months of follow up and only $2(10.0 \%)$ patients in group A and $4(23.5 \%)$ in group B were remained with neurological deficits which were in the form of mental retardation, hemiparesis and cranial nerve palsy. Statistically the difference in behaviour problems and neurological deficits in two groups is insignificant, but the numbers of patients with these problems are very less to show any difference. Minocycline is a clinically approved drug that shows high penetration across the blood-brain barrier. Because it is a safe, frequently used, inexpensive drug, it could be readily considered for testing in patients suffering from JE encephalitis. The limitation of our study is its small sample size. This study provides an initial evidence for the trial use of minocycline against the JE patients. However; detailed investigations and long term follow up in large sample would be required to establish the beneficial effect of minocycline against JE infection.

\section{Conclusion}

Minocycline has significant beneficial effect in JE patients in duration of major symptoms like fever and unconsciousness and duration of hospital stay. However, mortality and prevalence of neurological deficits and behavioral problems on follow up of these patients remain unchanged, but the sample size is very less to draw any conclusion. This study provides an initial evidence for the trial use of minocycline against the JE patients. A RCT with large sample size and long term follow up is required to establish the beneficial effects of minocycline in JE patients.

\section{Funding: Nil, Conflict of interest: Nil Permission from IRB: Yes}

\section{References}

1. Solomon T. Control of Japanese encephalitis - within our grasp? N Engl J Med. 2006; 355: 869-71.

2. Parida M, Dash PK, Tripathi NK, Ambuj, Sannarangalah S, Saxena P, et al. Japanese encephalitis outbreak, India. Emerg Infect Dis. 2006; 12: 1427-30.

3. Swarup V, Ghosh J, Ghosh S, Saxena A, Basu A. Antiviral and anti-inflammatory effects of rosmarinic acid in an experimental murine model of Japanese encephalitis. Antimicrob Agents Chemother. 2007 Sep;51(9):3367-70. Epub 2007 Jun 18.

4. Stancek d, Vilcek j, The role of interferon in tickborne encephalitis virus-infected 1 cells. I. Acute infection. Acta virol. 1965; 9:1-8.

5. Dutta K, Ghosh D and Basu A. Curcumin Protects Neuronal Cells from Japanese Encephalitis VirusMediated Cell Death and also Inhibits Infective Viral Particle Formation by Dysregulation of UbiquitinProteasome System. Journal of neuroimmune pharmacology 2009; 4(3): 328- 337.

6. Mishra MK, Basu A. Minocycline neuroprotects, reduces microglial activation, inhibits caspase 3 induction, and viral replication following Japanese encephalitis. J Neurochem. 2008; 105 (5):1582-95.

7. Anantpadma $M$ and Vrati S. SiRNA-mediated suppression of Japanese encephalitis virus replication in cultured cells and mice.J. Antimicrob. Chemother. 2011; 67 (2):444-451.

8. Kumar R, Tripathi P, Baranwal M, Singh S, Tripathi S, Banerjee G. Randomized, controlled trial of oral ribavirin for Japanese encephalitis in children in Uttar Pradesh, India. Clinical Infectious Diseases. 2009; 48: 400-4.

9. Sapadin AN, Fleischmajer R. Tetracyclines: nonantibiotic properties and their clinical implications. J Am Acad Dermatol. 2006; 54:258-65. 
10. Gordon PH, Moore DH, Miller RG, Florence JM, Verheijde JL, Doorish C, et al. Efficacy of minocycline in patients with amyotrophic lateral sclerosis: a phase III randomised trial. Lancet Neurol. 2007; 6: 1045-53.

11. Bonelli RM, Hödl AK, Hofmann P, Kapfhammer HP. Neuroprotection in Huntington's disease: a 2-year study on minocycline. Int Clin Psychopharmacol. 2004; 19(6):337-342.

12. Zink MC et al. "Neuroprotective and anti-human immunodeficiency virus activity of minocycline". JAMA . 2005; 293 (16): 2003-11.

13. Zabad RK, Metz LM, Todoruk TR, et al. The clinical response to minocycline in multiple sclerosis is accompanied by beneficial immune changes: a pilot study. Mult Scler. 2007; 13 (4):517-526.

14. Zhang Y, Metz LM, Yong VW, et al. Pilot study of minocycline in relapsing remitting multiple sclerosis. Can J Neurol Sci. 2008;35(2):185-191

15. Lemaitre M, Guetard D, Henin Y, Montagnier L, Zerial A. Protective activity of tetracycline analogs against the cytopathic effect of the human immunodeficiency viruses in CEM cells. Res Virol. 1990;141:5-16

16. Dutta K, Kumawat KL, Nazmi A, Mishra MK, Basu A. Minocycline differentially modulates viral infection and persistence in an experimental model of Japanese encephalitis. J Neuroimmune Pharmacol. 2010; 5(4): 553-65.

17. Michaelis M, Kleinschmidt MC, Doerr HW, Cinatl J Jr. Minocycline inhibits West Nile virus replication and apoptosis in human neuronal cells. J. Antimicrob Chemother. 2007; 60(5): 981-6.

18. Sapkal GN, Wairagkar NS, Ayachit VM, Bondre VP, Gore MM. Detection and isolation of Japanese encephalitis virus from blood clots collected during the acute phase of infection. Am J Trop Med Hyg. 2007; 77: 1139-45.
19. Lewthwaite P, Begum A, Ooi MH, etal. Disability after encephalitis: development and validation of a new outcome score. Bulletin of the World Health Organization 2010; 88:584-592. doi: 10.2471/BLT. 09.071357

20. Thomas M. Achenbach, Thomas M. Ruffle. The Child Behavior Checklist and Related Forms for Assessing Behavioral / Emotional Problems and Competencies. Pediatrics in Review Aug 2000, 21 (8) 255; doi: 10.1542/pir.21-8-255.

21. Labro MT. Immunomodulatory effects of antimicrobial agents. Part I: antibacterial and antiviral agents.Expert Rev Anti Infect Ther.2012; 10(3):319-40.

22. Chong CR, Sullivan DJ Jr. New uses for old drugs. Nature. 2007; 448: 645-6.

23. Dutta $\mathrm{K} \&$ Basu A. Use of minocycline in viral infections. Indian J Med Res. 2011; 133: 467-470.

24. Mishra MK, Ghosh D, Duseja R, Basu A. Antioxidant potential of minocycline in Japanese Encephalitis virus infection in murine neuroblastoma cells: correlation with membrane fluidity and cell death. neurochem Int. 2009; 54 : 464-70.

25. Mishra MK, Dutta K, Saheb SK, Basu A. Understanding the molecular mechanism of blood-brain barrier damage in an experimental model of Japanese encephalitis: correlation with minocycline administration as a therapeutic agent. Neurochem Int. 2009; 55: 717-23.

26. Jackson AC. Is minocycline useful for therapy of acute viral encephalitis? Antiviral Res. 2012; 95(3):242-4.

27. Yik et al. Neuroprotective effects of minocycline on double-stranded RNA-induced neurotoxicity in cultured cortical neurons. Hong Kong Med J. 2012; 2:42-44.

28. Sarkari NB,; Thacker AK,; Barthwal SP,; et al . Japanese encephalitis (JE) part II: 14 years' follow-up of survivors. J Neurol .2012; 259:58-69.

\section{How to cite this article?}

Singh A, Mehta A, Kushwaha KP, Pandey AK, Mittal M, Sharma B, Pandey J. Minocycline trial in japanese encephalitis: a double blind, randomized placebo study. Int J Pediatr Res.2016;3(5):371377.doi:10.17511/ijpr.2016.i05.18 